\title{
Postcentral Sulcus
}

National Cancer Institute

\section{Source}

National Cancer Institute. Postcentral Sulcus. NCI Thesaurus. Code C33347.

A prominent furrow or groove located on the parietal lobe of the brain posteriorly and parallel to the central sulcus and ending superiorly to the posterior ramus of the lateral fissure. 